\title{
Schoolverlaters tussen onderwijs en arbeidsmarkt 2020
}

Citation for published version (APA):

Graus, E., Huijgen, T., Belfi, B., \& Bakens, J. (2021). Schoolverlaters tussen onderwijs en arbeidsmarkt 2020. ROA. ROA Fact Sheets No. 004 https://doi.org/10.26481/umarof.2021004

Document status and date:

Published: 11/11/2021

DOI:

10.26481/umarof.2021004

Document Version:

Publisher's PDF, also known as Version of record

\section{Please check the document version of this publication:}

- A submitted manuscript is the version of the article upon submission and before peer-review. There can be important differences between the submitted version and the official published version of record.

People interested in the research are advised to contact the author for the final version of the publication, or visit the DOI to the publisher's website.

- The final author version and the galley proof are versions of the publication after peer review.

- The final published version features the final layout of the paper including the volume, issue and page numbers.

Link to publication

\footnotetext{
General rights rights.

- You may freely distribute the URL identifying the publication in the public portal. please follow below link for the End User Agreement:

www.umlib.nl/taverne-license

Take down policy

If you believe that this document breaches copyright please contact us at:

repository@maastrichtuniversity.nl

providing details and we will investigate your claim.
}

Copyright and moral rights for the publications made accessible in the public portal are retained by the authors and/or other copyright owners and it is a condition of accessing publications that users recognise and abide by the legal requirements associated with these

- Users may download and print one copy of any publication from the public portal for the purpose of private study or research.

- You may not further distribute the material or use it for any profit-making activity or commercial gain

If the publication is distributed under the terms of Article $25 \mathrm{fa}$ of the Dutch Copyright Act, indicated by the "Taverne" license above, 


\section{Maastricht University $\&$ ROA}

\section{Schoolverlaters tussen onderwijs en arbeidsmarkt 2020}

Evie Graus

Timo Huijgen

Barbara Belfi

Jessie Bakens

\section{ROA Factsheet}

\section{ROA-F-2021/4}

Researchcentrum voor Onderwijs en Arbeidsmarkt | ROA Research Centre For Education and the Labour Market / ROA 


\section{Transitie van school naar werk}
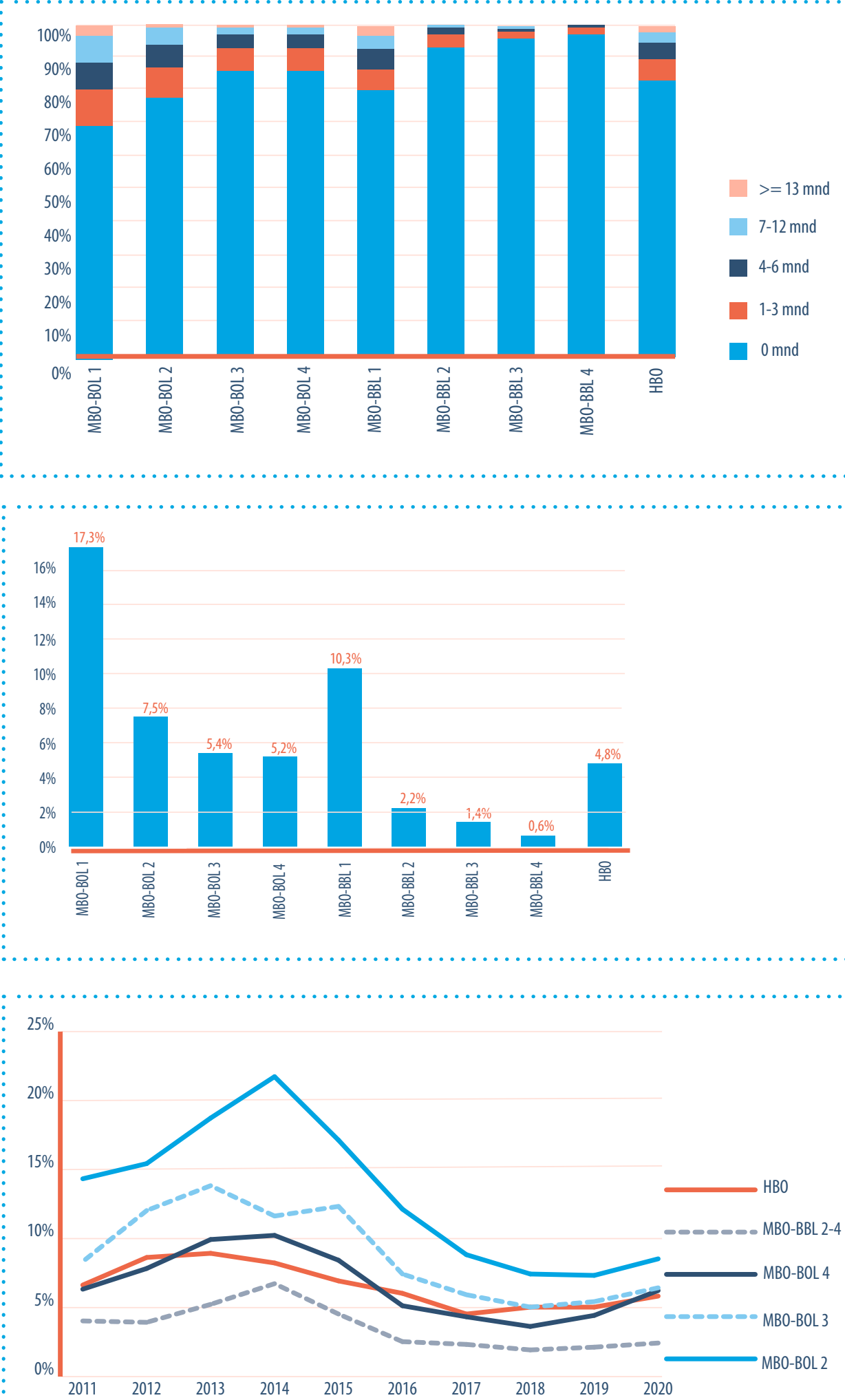

Intredewerkeloosheid na afronden van opleiding in schooljaar 2018-2019

Voor alle opleidingsniveaus geldt dat minimaal 81\% (mbo-bol niveau 1) va de gediplomeerden de eerste baan binnen drie maanden na behalen van het diploma vond.

Voor mbo-bbl niveaus 3 en 4 vond $96 \%$ zonder werkloosheidsperiode direct een baan.

Werkloosheid najaar 2020

Over alle opleidingsniveaus heen is $4,5 \%$ van de gediplomeerden die zich op de arbeidsmarkt aanbieden in het najaar van 2020 werkloos.

Gediplomeerden van het mbo-bol kennen op alle niveaus een hogere werkloosheid dan de gediplomeerden van het mbo-bbl. Over alle opleidingsniveaus heen is het werkeloosheidspercentage in het najor van 2020 rroter of in het werkeloosheid in 2019 .

Werkloosheid 2011-2018

De dalende trend in werkeloosheidscijfers die in eerdere jaren zichtbaar was heeft zich niet voortgezet in 2020. Voor alle opleidingsniveaus is een stijging in werkeloosheid te zien vergeleken met van mbo-bol.

\section{Kwaliteit van gevonden werk}

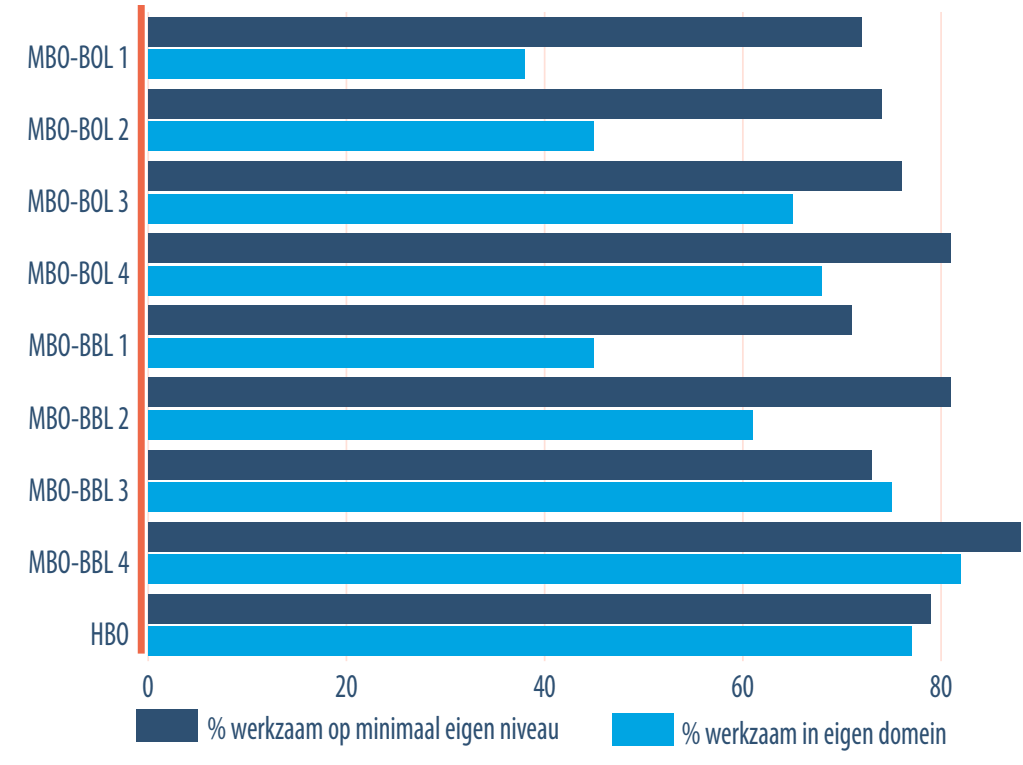

Aansluiting tussen opleiding en werk

Hoe hoger het niveau binnen het $\mathrm{mbo}$ hoe meer gediplomeerden aangeven dat ze werkzaam zijn binnen hun eigen domein.

Mbo-bbl-gediplomeerden hebben iets vaker een baan die qua niveau en richting bii de fferonde opleiding past dan mbo-bol-gediplomeerden

\begin{tabular}{|l|c|l|}
\hline MBO-BOL1 1 & Bruto uurloon \\
\hline MBO-BOL2 & 10,80 & \\
\hline MBO-BOL 3 & 10,70 & Het gemiddelde bruto-uurloon varieer \\
\hline MBO-BOL 4 & 12,26 & tussen $€ 10,80$ (mbo-bol niveau 1) en \\
\hline MBO-BBL 1 & 12,94 & $€ 16,69$ (mbo-bbl niveau 4). \\
\hline MBO-BBL2 & 11,19 & \\
\hline MBO-BBL3 & 13,09 & Het bruto-uurloon van mbo-bbl \\
\hline MBO-BBL 4 & 15,12 & niveau 4-gediplomeerden ligt 66 \\
\hline HBO & 16,69 & cent hoger dan dat van hbo-voltijd \\
\hline
\end{tabular}

\begin{tabular}{|c|c|c|c|}
\hline & $\begin{array}{l}\text { Tevredenheid } \\
\text { met functie }\end{array}$ & $\begin{array}{l}\text { Goede carrière- } \\
\text { perspectieven }\end{array}$ & Tevredenheid met werk \\
\hline MBO-BOL 1 & 75 & 40 & \multirow{9}{*}{$\begin{array}{l}\text { Minimaal } 72 \% \text { van de werkende } \\
\text { gediplomeerden is tevreden met de } \\
\text { huidige functie. Tussen } 40 \% \text { (mbo- } \\
\text { bbl niveau 1) en } 65 \% \text { (hbo) van de } \\
\text { gediplomeerden is tevreden met de } \\
\text { carrièreperspectieven die hun huidige } \\
\text { functie biedt. Dit percentage is hoger } \\
\text { over alle opleidingsniveaus dan in } \\
2019 \text {. }\end{array}$} \\
\hline MBO-BOL 2 & 80 & 51 & \\
\hline MBO-BOL 3 & 81 & 52 & \\
\hline MBO-BOL 4 & 80 & 52 & \\
\hline MBO-BBL 1 & 72 & 44 & \\
\hline MBO-BBL 2 & 83 & 55 & \\
\hline MBO-BBL 3 & 84 & 56 & \\
\hline MBO-BBL 4 & 83 & 55 & \\
\hline HBO & 72 & 65 & \\
\hline
\end{tabular}




\section{Vervolgonderwijs}
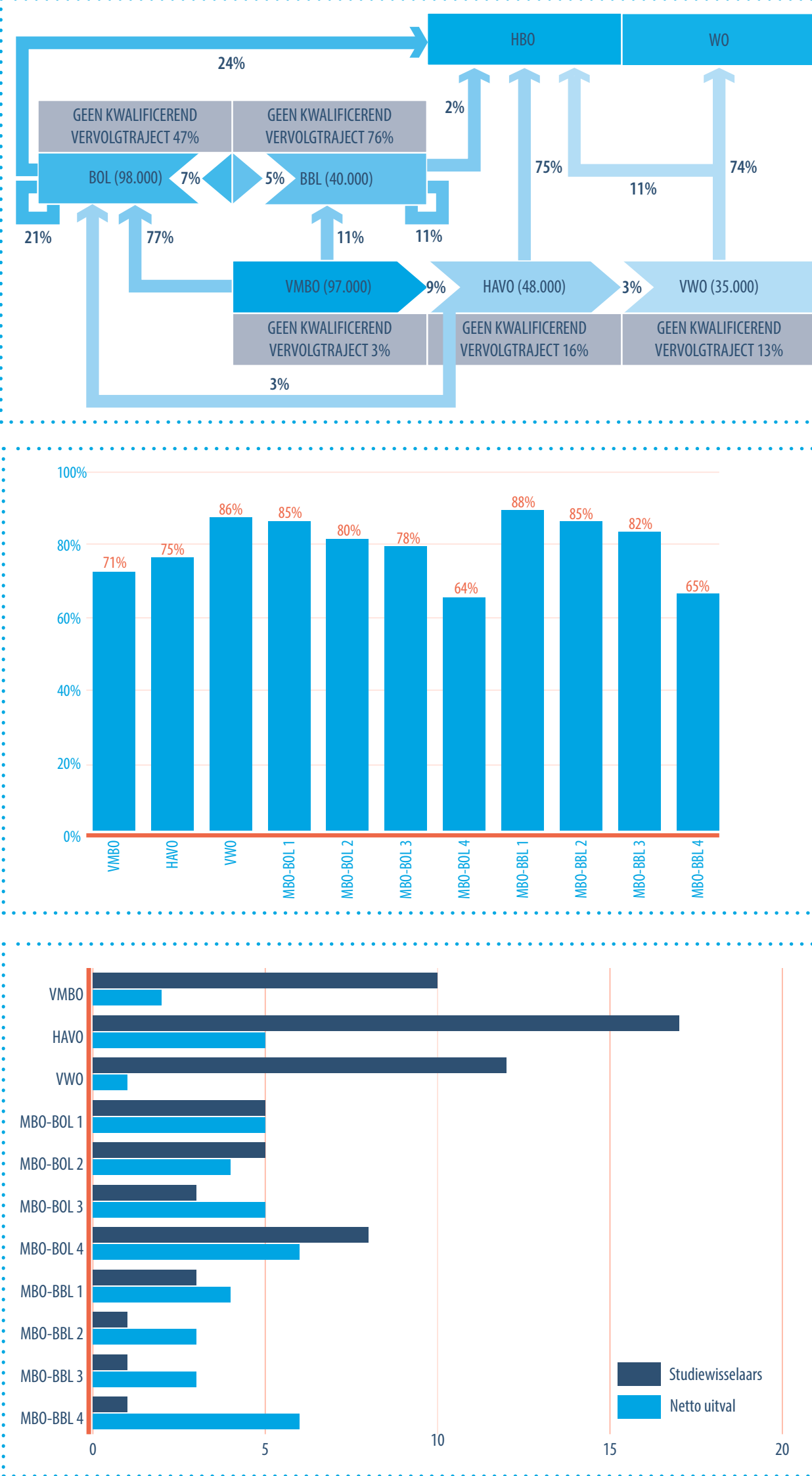

\section{Tevredenheid met afgeronde opleiding}

Kwalificerende vervolgtrajecten

De doorstroom van vmbo naar havo $(9 \%)$ en van havo naar vwo (3\%) blijf laag. $16 \%$ van de gediplomeerden van de havo en $13 \%$ van de gediplomeerden van het vwo studeren niet direct verder. Voldoende/goede gediplomeerden)

Bij alle onderwijsniveaus is een grote meerderheid van mening dat de aansluiting tussen de eerder gevolgde opleiding en de vervolgopleiding redelijk tot goed is.

Gediplomeerden van het mbo niveau 4 die doorstromen naar het hbo zijn het meest kritisch: ongeveer 1 op de 3 beoordeelt de aansluiting als matig of zelfs slecht.

\section{Netto uitval en} studiewisselaars

Onder de gediplomeerden van het voortgezet onderwijs die met een vervolgopleiding zijn gestart, komen binnen het eerste anderhalf jaar de meeste studiewisselaars voor bij de havo $(17 \%)$ gevolgd door het (12\%) en vmbo (10\%) $6 \%$ van de gediplomerden van nedrear 4 en mbo-bal niveau 4 en mbo-bbl niveau 4 die vervolgopleiding start, valt uit.

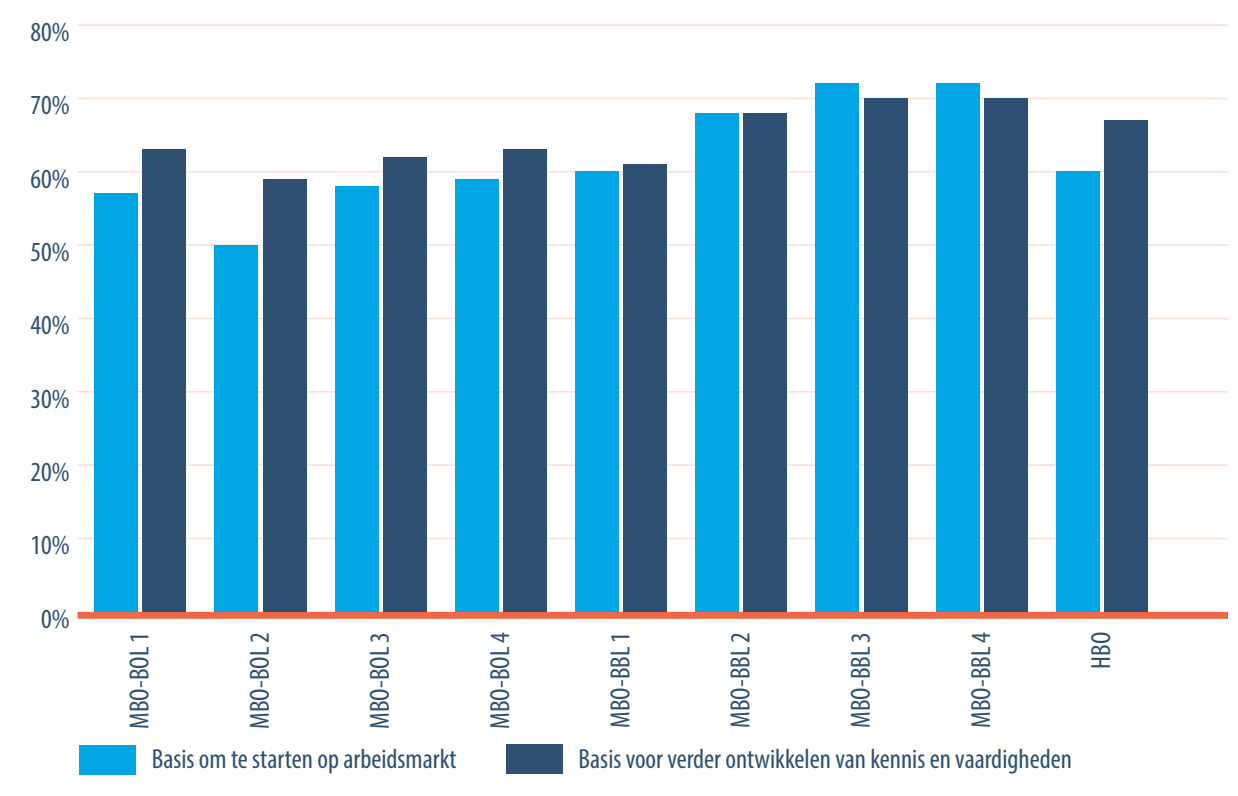

Voorbereiding op

arbeidsmarkt en verder leren (oordeel gediplomeerden)

Gediplomeerden van het mbo-bbl vinden vaker dat de opleiding een goede basis voor de arbeidsmarkt bood dan gediplomeerden van mbo-bol dit vinden.

Ook zijn de gediplomeerde van mbo-bbl over het algemeen meer tevreden over de basis die de afgeronde opleiding bood voor het verder ontwikkelen van kennis en vaardigheden. Van de afgestudeerde hbo'ers vindt $67 \%$ dat zijn of haar studie een goede basis bood.

\begin{tabular}{|l|c|c|}
\hline VMBO & Dezelfde opleiding & $\begin{array}{c}\text { Opleiding was uitdagend } \\
\text { qua niveau }\end{array}$ \\
\hline MBO-BOL 1 & 71 & 34 \\
\hline MBO-BOL2 & 58 & 41 \\
\hline MBO-BOL 3 & 56 & 32 \\
\hline MBO-BOL 4 & 65 & 40 \\
\hline MBO-BBL 1 & 70 & 35 \\
\hline MBO-BBL2 & 63 & 49 \\
\hline MBO-BBL 3 & 70 & 42 \\
\hline MBO-BBL 4 & 74 & 46 \\
\hline HBO & 77 & 45 \\
\hline Total & 78 & 37 \\
\hline
\end{tabular}

Tevredenheid met studiekeuze achteraf en vraag of opleiding uitdagend was

Op alle niveaus zou minimaal $56 \%$ van de gediplomeerde schoolverlaters dezelfde opleiding opnieuw kiezen. Slechts $32 \%$ van de gediplomeerden bij het mbo-bol niveau 2 tot $49 \%$ van de gediplomeerden bij mbo-bbl niveau 1 is het ermee eens dat zijn/ haar opleiding uitdagend genoeg was. 
Algemeen

\begin{tabular}{|c|c|c|c|c|c|}
\hline & & $\begin{array}{l}\text { Gevolgde opleiding } \\
\text { achteraf: starten op } \\
\text { arbeidsmarkt } \\
\%\end{array}$ & $\begin{array}{l}\text { Gevolgde opleiding } \\
\text { achteraf: verder } \\
\text { ontwikkelen } \\
\%\end{array}$ & $\begin{array}{c}\begin{array}{c}\text { Opleiding achteraf } \\
\text { opnieuw kiezen }\end{array} \\
\%\end{array}$ & $\begin{array}{c}\text { Opleiding was uitdagend } \\
\text { qua nivea } \\
\%\end{array}$ \\
\hline VMBO & & & 59 & 71 & 34 \\
\hline \multirow[t]{4}{*}{ VMBO Naar leerweg } & Theoretisch & & 61 & 74 & 30 \\
\hline & Gemengd & & 58 & 74 & 38 \\
\hline & Kaderberoepsgericht & & 58 & 71 & 41 \\
\hline & Basisberoepsgericht & & 55 & 61 & 34 \\
\hline \multirow{5}{*}{ VMBO naar sector } & Landbouw & & 53 & 64 & 36 \\
\hline & Techniek & & 61 & 70 & 45 \\
\hline & Economie & & 56 & 69 & 34 \\
\hline & Gezondheidszorg & & 57 & 69 & 40 \\
\hline & Intersectoraal & & 56 & 67 & 35 \\
\hline MBO Totaal & & 61 & 64 & 68 & 38 \\
\hline BOL Totaal & & 57 & 62 & 65 & 36 \\
\hline MBO-BOL 1 & & 57 & 63 & 58 & 41 \\
\hline MBO-BOL 2 & & 50 & 59 & 56 & 32 \\
\hline \multirow[t]{4}{*}{ MBO-BOL 2} & Landbouw & 45 & 56 & 59 & 33 \\
\hline & Techniek & 47 & 56 & 58 & 38 \\
\hline & Economie & 52 & 60 & 58 & 30 \\
\hline & Gezondheidszorg & 49 & 60 & 54 & 31 \\
\hline MBO-BOL 3 & & 58 & 62 & 65 & 40 \\
\hline \multirow[t]{5}{*}{ MBO-BOL 3} & Landbouw & 52 & 55 & 62 & 38 \\
\hline & Techniek & 57 & 61 & 65 & 40 \\
\hline & Economie & 53 & 62 & 61 & 37 \\
\hline & Gezondheidszorg & 66 & 63 & 69 & 44 \\
\hline & Gedrag en maatschappij & 73 & 60 & 72 & 47 \\
\hline MBO-BOL 4 & & 59 & 63 & 70 & 35 \\
\hline \multirow[t]{5}{*}{ MBO-BOL 4} & Landbouw & 54 & 59 & 68 & 36 \\
\hline & Techniek & 61 & 63 & 71 & 37 \\
\hline & Economie & 50 & 60 & 65 & 29 \\
\hline & Gezondheidszorg & 70 & 67 & 75 & 43 \\
\hline & Gedrag en maatschappij & 63 & 64 & 73 & 31 \\
\hline BBL Totaal & & 70 & 69 & 73 & 45 \\
\hline MBO-BBL 1 & & 60 & 61 & 63 & 49 \\
\hline
\end{tabular}

\begin{tabular}{|c|c|c|c|c|c|}
\hline & & $\begin{array}{l}\text { Gevolgde opleiding } \\
\text { achteraf: starten op } \\
\text { arbeidsmarkt }\end{array}$ & $\begin{array}{l}\text { Gevolgde opleiding } \\
\text { achteraf: verder } \\
\text { ontwikkelen }\end{array}$ & $\begin{array}{c}\text { Opleiding achteraf } \\
\text { opnieuw kiezen }\end{array}$ & $\begin{array}{l}\text { Opleiding was uitdagend } \\
\text { qua nivea }\end{array}$ \\
\hline & & & & & \\
\hline MBO-BBL 2 & & 68 & 68 & 70 & 42 \\
\hline \multirow[t]{4}{*}{ MBO-BBL 2} & Landbouw & 65 & 70 & 64 & 46 \\
\hline & Techniek & 68 & 67 & 73 & 45 \\
\hline & Economie & 66 & 64 & 66 & 35 \\
\hline & Gezondheidszorg & 74 & 76 & 71 & 46 \\
\hline MBO-BBL 3 & & 72 & 70 & 74 & 46 \\
\hline \multirow[t]{5}{*}{ MBO-BBL 3} & Landbouw & 63 & 63 & 66 & 37 \\
\hline & Techniek & 71 & 68 & 80 & 50 \\
\hline & Economie & 65 & 64 & 66 & 35 \\
\hline & Gezondheidszorg & 79 & 77 & 73 & 50 \\
\hline & Gedrag en maatschappij & 83 & 81 & 84 & 53 \\
\hline MBO-BBL 4 & & 72 & 70 & 77 & 45 \\
\hline \multirow{5}{*}{ MBO-BBL 4} & Landbouw & 67 & 64 & 68 & 46 \\
\hline & Techniek & 74 & 74 & 80 & 53 \\
\hline & Economie & 61 & 64 & 68 & 36 \\
\hline & Gezondheidszorg & 77 & 72 & 81 & 46 \\
\hline & Gedrag en maatschappij & 68 & 66 & 75 & 42 \\
\hline HBO & & 60 & 67 & 78 & \\
\hline \multirow[t]{7}{*}{ HBO } & Landbouw & 63 & 72 & 79 & \\
\hline & Onderwijs & 76 & 61 & 86 & \\
\hline & Techniek & 66 & 71 & 83 & \\
\hline & Economie & 57 & 64 & 72 & \\
\hline & Gezondheidszorg & 68 & 71 & 85 & \\
\hline & Gedrag en maatschappij & 57 & 66 & 79 & \\
\hline & Taal en cultuur & 31 & 74 & 84 & \\
\hline & & & & & \\
\hline
\end{tabular}

1. Gevolgde opleiding achteraf: starten op arbeidsmarkt $=\%$ dat van mening is dat opleiding een (zeer) goede basis bood om te starten op de arbeidsmarkt. 2. Gevolgde opleiding achteraf: verder ontwikkelen $=\%$ dat

voor het verder ontwikkelen van kennis en vaardigheden.

. Opleiding was uitdagend qua niveau $=\%$ dat (helemaal) mee eens is dat het niveau van de opleiding uitdagend was.

4. Opleiding achteraf opnieuw kiezen $=\%$ dat achteraf gezien dezelfde opleiding opnieuw zou kiezen (aan dezelfde of aan

een andere school).

5. Antwoordcategorie 4 of 5 op een schaal van 1 (helemaal niet) tot en met 5 (in sterke mate) 


\begin{tabular}{|c|c|c|c|c|}
\hline & & $\begin{array}{l}\text { Aansluiting goed/redelijk } \\
\%\end{array}$ & $\begin{array}{l}\text { Gestopt } \\
\%\end{array}$ & $\begin{array}{l}\text { Gestopt en studie gewisseld } \\
\%\end{array}$ \\
\hline HAVO/VWOTotaal & & 80 & 3 & 14 \\
\hline HAVO & & 75 & 5 & 17 \\
\hline vwo & & 86 & 1 & 12 \\
\hline VMBO & & 71 & 2 & 10 \\
\hline \multirow{4}{*}{ VMBO Naar leerweg } & Theoretisch & 70 & 2 & 11 \\
\hline & Gemengd & 73 & 1 & 10 \\
\hline & Kaderberoepsgericht & 71 & 3 & 12 \\
\hline & Basisberoepsgericht & 76 & 3 & 7 \\
\hline \multirow[t]{6}{*}{ VMBO naar sector } & Landbouw & 69 & 3 & 8 \\
\hline & Techniek & 73 & 3 & 8 \\
\hline & Economie & 71 & 2 & 10 \\
\hline & Gezondheidszorg & 76 & 3 & 10 \\
\hline & Intersectoraal & 72 & 2 & 12 \\
\hline & Intersectoraal & 77 & 3 & 5 \\
\hline MBO Totaal & & 73 & 5 & 5 \\
\hline & & & & \\
\hline BOL Totaal & & 72 & 5 & 6 \\
\hline MBO-BOL 1 & & 85 & 5 & 5 \\
\hline MBO-BOL2 & & 80 & 4 & 5 \\
\hline \multirow[t]{4}{*}{ MBO-BOL2 } & Landbouw & 86 & 7 & 4 \\
\hline & Techniek & 80 & 4 & 4 \\
\hline & Economie & 78 & 5 & 5 \\
\hline & Gezondheidszorg & 82 & 4 & 6 \\
\hline MBO-BOL 3 & & 78 & 5 & 3 \\
\hline \multirow[t]{5}{*}{ MBO-BOL 3} & Landbouw & 81 & 6 & 3 \\
\hline & Techniek & 78 & 5 & 3 \\
\hline & Economie & 76 & 4 & 5 \\
\hline & Gezondheidszorg & 81 & 4 & 2 \\
\hline & Gedrag en maatschappij & 80 & 7 & 2 \\
\hline MBO-BOL 4 & & 64 & 6 & 8 \\
\hline \multirow[t]{5}{*}{ MBO-BOL 4} & Landbouw & 57 & 9 & 8 \\
\hline & Techniek & 62 & 6 & 6 \\
\hline & Economie & 64 & 5 & 8 \\
\hline & Gezondheidszorg & 62 & 5 & 7 \\
\hline & Gedrag en maatschappij & 68 & 8 & 8 \\
\hline BBL Totaal & & 81 & 4 & 1 \\
\hline MBO-BBL 1 & & 88 & 4 & 3 \\
\hline MBO-BBL 2 & & 85 & 3 & 1 \\
\hline MBO-BBL 3 & & 82 & 3 & 1 \\
\hline MBO-BBL 4 & & 65 & 6 & 1 \\
\hline
\end{tabular}

\begin{tabular}{|c|c|c|c|c|}
\hline & & $\begin{array}{l}\text { Aansluiting goed/redelijk } \\
\% \%\end{array}$ & $\begin{array}{l}\text { Gestopt } \\
\%\end{array}$ & $\underset{\%}{\text { Gestopt en studie gewisseld }}$ \\
\hline HBO & & 75 & 6 & 1 \\
\hline \multirow[t]{7}{*}{ HBO } & Landbouw & 74 & 5 & 0 \\
\hline & Onderwiis & 83 & 6 & 0 \\
\hline & Techniek & 74 & 6 & 1 \\
\hline & Economie & 73 & 6 & 1 \\
\hline & Gezondheidszorg & 82 & 4 & 0 \\
\hline & Gedrag en maatschappij & 75 & 8 & 0 \\
\hline & Taal en cultuur & $x$ & 6 & 0 \\
\hline Totaal & & 75 & 3 & 10 \\
\hline 1. & \multicolumn{4}{|c|}{$\begin{array}{l}\text { Aansluiting: goed/redelijk = \% dat van mening is dat de aansluiting tussen de afgeronde opleiding en de gekozen } \\
\text { vervolgopleiding goed dan wel redelijk is. }\end{array}$} \\
\hline 2. & \multicolumn{4}{|c|}{$\begin{array}{l}\text { Gestopt }=\% \text { dat op moment van enquête alweer gestopt is met vervolgopleiding en op moment van enquête niet in } \\
\text { het onderwijs zit. }\end{array}$} \\
\hline 3. & \multicolumn{4}{|c|}{$\begin{array}{l}\text { Gestopt en studie gewisseld = \% dat op moment van enquête alweer is gestopt met vervolgopleiding en op moment } \\
\text { van enquête met een studie bezig is. }\end{array}$} \\
\hline
\end{tabular}


Arbeidsmarkt

\begin{tabular}{|c|c|c|c|c|c|c|c|}
\hline & & $\begin{array}{c}\text { Minimaal op } \\
\text { eigen niveau } \\
\%\end{array}$ & $\begin{array}{c}\text { Eigen/verwante } \\
\text { richting } \\
\% \\
\%\end{array}$ & $\begin{array}{c}\begin{array}{c}\text { Aansluiting } \\
\text { goed/voldoende }\end{array} \\
\%\end{array}$ & $\begin{array}{c}\begin{array}{c}\text { Werkloze } \\
\text { beroepsbevolking }\end{array} \\
\%\end{array}$ & $\begin{array}{c}\text { Zoekduur eerste } \\
\text { baan in klassen } \\
>3 \mathrm{mnd} . \\
\%\end{array}$ & $\begin{array}{c}\text { Gemiddeld } \\
\text { bruto uurloon } \\
€\end{array}$ \\
\hline MBO Totaal & & 79 & 67 & 79 & 4,3 & 6 & 13,55 \\
\hline BOL Totaal & & 79 & 63 & 73 & 6,1 & 9 & 12,43 \\
\hline MBO-BOL 1 & & 72 & 38 & 67 & 17,3 & 19 & 10,80 \\
\hline MBO-BOL 2 & & 74 & 45 & 64 & 7,5 & 13 & 10,70 \\
\hline \multirow[t]{4}{*}{ MBO-BOL 2} & Landbouw & 72 & 41 & 57 & 4 & 8 & 8,95 \\
\hline & Techniek & 74 & 49 & 65 & 7,4 & 11 & 10,24 \\
\hline & Economie & 73 & 41 & 67 & 6,8 & 13 & 10,42 \\
\hline & Gezondheidszorg & 76 & 48 & 63 & 9,1 & 16 & 11,81 \\
\hline MBO-BOL 3 & & 76 & 65 & 76 & 5,4 & 8 & 12,26 \\
\hline \multirow[t]{5}{*}{ MBO-BOL 3} & Landbouw & 66 & 53 & 68 & 5,5 & 9 & 9,84 \\
\hline & Techniek & 76 & 66 & 75 & 5,3 & 9 & 12,56 \\
\hline & Economie & 69 & 52 & 68 & 9,2 & 12 & 10,97 \\
\hline & Gezondheidszorg & 78 & 76 & 82 & 2,4 & 4 & 13,29 \\
\hline & $\begin{array}{l}\text { Gedrag en } \\
\text { maatschappij }\end{array}$ & 94 & 80 & 90 & 2,8 & 4 & 13,91 \\
\hline MBO-BOL 4 & & 81 & 68 & 74 & 5,2 & 7 & 12,94 \\
\hline \multirow[t]{5}{*}{ MBO-BOL 4} & Landbouw & 70 & 59 & 69 & 1,9 & 6 & 11,43 \\
\hline & Techniek & 79 & 66 & 72 & 6,3 & 10 & 12,80 \\
\hline & Economie & 77 & 53 & 63 & 7,3 & 9 & 11,39 \\
\hline & Gezondheidszorg & 88 & 81 & 84 & 2,4 & 3 & 14,79 \\
\hline & $\begin{array}{l}\text { Gedrag en } \\
\text { maatschappij }\end{array}$ & 87 & 78 & 80 & 4,8 & 6 & 13,40 \\
\hline BBL Totaal & & 79 & 72 & 88 & 1,7 & 2 & 14,93 \\
\hline MBO-BBL 1 & & 71 & 45 & 76 & 10,3 & 13 & 11,19 \\
\hline MBO-BBL 2 & & 81 & 61 & 86 & 2,2 & 3 & 13,09 \\
\hline \multirow[t]{4}{*}{ MBO-BBL 2} & Landbouw & 76 & 56 & 82 & 2,7 & 3 & 12,04 \\
\hline & Techniek & 85 & 65 & 86 & 0,6 & 2 & 13,46 \\
\hline & Economie & 74 & 49 & 82 & 4,2 & 4 & 11,35 \\
\hline & Gezondheidszorg & 84 & 71 & 92 & 2,9 & 5 & 15,35 \\
\hline MBO-BBL 3 & & 73 & 75 & 89 & 1,4 & 2 & 15,12 \\
\hline \multirow[t]{5}{*}{ MBO-BBL 3} & Landbouw & 63 & 63 & 88 & 1,1 & 2 & 12,74 \\
\hline & Techniek & 68 & 77 & 89 & 1 & 1 & 15,54 \\
\hline & Economie & 63 & 58 & 83 & 4,1 & 5 & 11,78 \\
\hline & Gezondheidszorg & 85 & 83 & 94 & 0,3 & 1 & 16,92 \\
\hline & $\begin{array}{l}\text { Gedrag en } \\
\text { maatschappij }\end{array}$ & 90 & 91 & 98 & 0 & 1 & 17,40 \\
\hline MBO-BBLC & & 88 & 82 & 89 & 0,6 & 1 & . \\
\hline
\end{tabular}

\begin{tabular}{|c|c|c|c|c|c|c|c|}
\hline & & $\begin{array}{c}\text { Minimaal op } \\
\text { eigen niveau } \\
\%\end{array}$ & $\begin{array}{c}\text { Eigen/verwante } \\
\text { richting } \\
\%\end{array}$ & $\begin{array}{c}\text { Aansluiting } \\
\text { goed/voldoende } \\
\%\end{array}$ & $\begin{array}{c}\begin{array}{c}\text { Werkloze } \\
\text { beroepsbevolking }\end{array} \\
\%\end{array}$ & $\begin{array}{c}\text { Zoekduur eerste } \\
\text { baan in klassen } \\
>3 \text { mnd. } \\
\%\end{array}$ & $\begin{array}{c}\text { Gemiddeld } \\
\text { bruto uurloon } \\
\epsilon\end{array}$ \\
\hline \multirow[t]{5}{*}{ MBO-BBL 4} & Landbouw & 78 & 61 & 90 & 0 & 0 & 15,00 \\
\hline & Techniek & 81 & 81 & 89 & 0,6 & 0 & 16,05 \\
\hline & Economie & 83 & 64 & 82 & 1,4 & 4 & 13,39 \\
\hline & Gezondheidszorg & 94 & 90 & 92 & 0,4 & 1 & 18,54 \\
\hline & $\begin{array}{l}\text { Gedrag en } \\
\text { maatschappij }\end{array}$ & 96 & 88 & 90 & 0,2 & 1 & 16,62 \\
\hline HBO & & 79 & 77 & 77 & 4,8 & 10 & 16,03 \\
\hline \multirow[t]{7}{*}{ HBO } & Landbouw & 77 & 69 & 76 & 5,1 & 10 & 15,18 \\
\hline & Onderwijs & 94 & 90 & 88 & 1 & 3 & 16,72 \\
\hline & Techniek & 86 & 82 & 79 & 5,8 & 11 & 16,37 \\
\hline & Economie & 82 & 66 & 70 & 6,5 & 12 & 15,60 \\
\hline & Gezondheidszorg & 80 & 89 & 85 & 1,8 & 5 & 17,59 \\
\hline & $\begin{array}{l}\text { Gedrag en } \\
\text { maatschappij }\end{array}$ & 66 & 84 & 79 & 3,1 & 7 & 16,21 \\
\hline & Taal en cultuur & 59 & 65 & 68 & 8,7 & 17 & 13,21 \\
\hline
\end{tabular}

Totaal $\begin{array}{ll}79 & 71 \\ \text { is afgerond op } 10 \text { cent. }\end{array}$

Het gemiddeld bruto uurloon is afge

Minimaal op eigen niveau $=\%$ dat aangeeft dat voor de gevonden functie een opleidingsniveau minimaal gelijk aan de afgeronde opleiding door de werkgever vereist werd

2. Eigen/verwante richting $=\%$ dat aangeeft dat voor de gevonden functie uitsluitend de eigen studierichting dan wel de eigen of een verwante studierichting door de werkgever vereist werd.

. Aansluiting goed/voldoende $=\%$ dat van mening is dat de aansluiting tussen de afgeronde opleiding en de gevonden functie goed dan wel voldoende is.

4. Werkloze beroepsbevolking $=\%$ dat zich op de arbeidsmarkt aanbiedt (exclusief respondenten die zich als student zien) en dat niet werkzaam (=o uur) is en tegelijkertijd op zoek naar werk is.

5. Zoekduur eerste baan in klassen $>3 \mathrm{mnd}$. $=\%$ dat tussen behalen van diploma en vinden van eerste baan minimaal 4 maanden werkloos was.

6. Gemiddeld bruto uurloon = uurloon berekend op basis van maandinkomen en aantal uren werkzaam per week in hoofdfunctie. 


\section{Over de data}

1. Het schoolverlatersonderzoek beoogt een monitoringsinstrument van de transitie van school naar werk over de volle breedte van het onderwijs. Naast instrument voor kwaliteitszorg ten behoeve van onderwijsinstellingen dienen de gegevens vooral als een landelijk representatieve databron waarvan de maatschappelijke en wetenschappelijke betekenis ligt in het vergroten van het inzicht in de transitie van school naar werk.

2. De cijfers met betrekking tot het hbo hebben betrekking op afgestudeerden van voltijdopleidingen en zijn afkomstig van de HBO-Monitor die het ROA in samenwerking met DESAN Research Solutions onder auspiciën van de Vereniging Hogescholen en in opdracht van de hogescholen uitvoert. Ruim 29.000 respondenten hebben de enquête voor de HBO-Monitor ingevuld. De respons is daarmee $44 \%$ van de benaderde afgestudeerden. Voor meer informatie, zie ook www.hbomonitor.nl.

3. De cijfers met betrekking tot vmbo, avo en mbo zijn afkomstig van het Schoolverlatersonderzoek dat het CBS in samenwerking met het ROA uitvoert. 42824 respondenten van het vmbo, avo en mbo hebben de vragenlijst ingevuld, wat neerkomt op een aandeel van $29.1 \%$

4. De enquêtes vonden plaats in het najaar van 2020 onder gediplomeerden en afgestudeerden van het schooljaar 2018-2019.

5. Meer cijfers zijn te vinden via: https://roastatistics.maastrichtuniversity.nl/.

\section{Definities}

1. Werkloze beroepsbevolking $=\%$ dat zich op de arbeidsmarkt aanbiedt (exclusief respondenten die zich als student zien) en dat niet werkzaam (=o uur) is en tegelijkertijd op zoek naar werk is.

2. Werkzaam op eigen niveau = respondent geeft aan dat voor het werk dat hij of zij uitvoert minimaal een diploma op het eigen onderwijsniveau vereist is.

3. Werkzaam in eigen domein = respondent geeft aan dat voor het werk dat hij of zij uitvoert de eigen, dan wel een verwante, opleidingsrichting het beste voorbereid.

4. Tevredenheid met functie/ Tevredenheid met carrierperspectieven/Voorbereiding op arbeidsmarkt/ Voorbereiding op verder leren: Figuren/Tabellen presenteren \% dat antwoordcategorie 4 of 5 op een 5-punt Likert schaal afvinkte.

\section{Contactpersonen}

Barbara Belfi, b.belfi@maastrichtuniversity.nl

Jessie Bakens, j.bakens@maastrichtuniversity.nl

\section{Colofon}

() Researchcentrum voor Onderwijs en Arbeidsmarkt

Niets uit deze uitgave mag op enige manier worden verveelvoudigd zonder voorafgaande schriftelijke toestemming van de directeur van het ROA.

\section{Researchcentrum voor Onderwijs en Arbeidsmarkt}

Maastricht University

School of Business and Economics

secretary-roa-sbe@maastrichtuniversity.nl www.roa.nl

Deze factsheet is uitgebracht in het kader Deze factsheet is uitgebracht in het kader van het Project Onderwijs-Arbeidsmarkt (POA; https://roa.nl/research/research-projects/project-onderwijs-arbeidsmarkt-poa) mede dankzij financiering van NRO (dossiernummer 405-17-900), UWV, S-BB en Randstad

\section{Vormgeving}

ROA secretariaat, Maastricht 